\title{
A Study on Optimized Design Method of the Pre-machined Hole for Flanging of Square Tributary Junction on Cylindrical Steel Tube
}

\author{
Li-Zhaodong ${ }^{1, a}$, Wang-Zhonglei ${ }^{* 1, b}$, Hao-Sheke $^{1, c}$, Liu-Pengyao ${ }^{1, d}$ \\ ${ }^{1}$ School of Mechanical and Electrical Engineering, Shandong Jianzhu University, Fengming Road, \\ Lingang Development Zone, Jinan, Shandong Province, P. R. China. \\ awade_thunder@163.com, bwangzhognlei005@163.com, \\ c1025804271@qq.com, ${ }^{d} 153772779 @ q q . c o m$
}

\begin{abstract}
Keywords: Flanging of Square Tributary Junction, Pre-Machined Hole, FE Simulation, Optimized Design

Abstract. Critical for flanging of square tributary junction on cylindrical steel tube is to determine the shape and sizes of pre-machined hole. In order to investigate precise shape and sizes of the pre-machined hole, an optimized design model is established. The forming process during flanging is simulated with the aid of FE-simulation software, and the target function for optimized design is calculated based on results of the simulations. In order to increase the convergence rate of the optimized design, a mathematical model of pre-machined hole for flanging on the tube is established based on isoline theory, the results are used as initial values for optimized design. To verify its accuracy the optimized design is carried out based on a typical flanging of square tributary junction on cylindrical steel tube. The results of the optimized design meet the technological requirements.
\end{abstract}

\section{Introduction}

With the development in economics and technology, the demands for T-shape tube, which is key component for connecting of large tube nets, is also increasing. For the process design of flanging of square tributary junction on steel tube, the critical issue is to determine the shape and sizes of pre-machined hole precisely, for this an optimized design method is researched in this paper.

A lot of works have been done by the researchers, Luo Yatao [1] has simplified the pre-machined hold as an ellipse, and calculated the long and short axis of the ellipse using special positions, and further investigated the shape and sizes of the pre-machined ellipse; Liu Jianshen et. [2-4] have carried out experimental and numerical study on flanging on tube with thick wall thickness; Liu Limin [5] has researched the flanging of $\mathrm{T}$-shape tube with greater diameter based on experimental and simulation method; Li Zhaodong et. [6] have introduced a method to determine the pre-machined hole based on revising method, which combines theoretical formula derivation and finite element; Bai Yanchao [7] has optimized the cutting edges based on deviation correction method; $\mathrm{Gu} \mathrm{Li} \mathrm{[8]} \mathrm{has} \mathrm{simplified} \mathrm{the}$ pre-machined hole as an ellipse to optimize the parameters for flanging of T-shape tube with greater diameter, in which the long and short axis of an ellipse being as optimized design variables, the neural network system being as the optimized target function solver, and genetic algorithm is used.

In the aforementioned researches the optimized design method based on optimized algorithm is of high degree of automation and reliability. Yet the accuracy of the optimized design method to determination of pre-machined hole is not high, the reason is that the pre-machined hole by simplifying is regarded as an ellipse, it could not describe the shape of the pre-machined hole precisely. In this paper an optimized model is established, in which the shape of the pre-machined hole is controlled with spline curves, and spline curves are controlled with points, so a high accuracy of pre-machined hole in the optimized design can be achieved.

\section{Establishment of Optimized Model}

The establishing of an optimized model includes three aspects: choosing of optimized design variables, listing of optimized target function, definition of the constraints. Because of symmetry in geometrical shape, only $1 / 4$ of pre-machined hole is taken as research objective to speed up the effectiveness of the 
optimized design. Since the pre-machined hole is a continuous spatial geometric curve, and variables for the optimized design are only some limited data, so the continuous spatial geometric curve has to be discredited. The established optimized model in this paper is as follows:

Optimized design variables: $\left(x_{1}, y_{1}\right),\left(x_{2}, y_{2}\right) \mathrm{L}\left(x_{n}, y_{n}\right)$

Target function of optimized design:

$$
F\left(x_{1}, y_{1}, x_{2}, y_{2} \mathrm{~L} x_{n}, y_{n}\right)=\sqrt{\left(\left(H_{1}-H\right)^{2}+\left(H_{2}-H\right)^{2}+\mathrm{L}+\left(H_{n}-H\right)^{2}\right) / n}
$$

Optimized constraints: (1) cracks or wrinkles should not be aroused on the parts;

$$
\text { (2) } H_{\max }-H_{\min } \leq \Delta H
$$

Among them, $\left(x_{1}, y_{1}\right),\left(x_{2}, y_{2}\right) \mathrm{L}\left(x_{n}, y_{n}\right)$ are coordinates of discrete points of the pre-machined hole; $\left(\begin{array}{llll}H_{1} & H_{2} & \mathrm{~L} & H_{n}\end{array}\right)$ are flanged heights in various positions. $H_{\max }, H_{\min }$ are maximal and minimal height of flanged height in all positions; $\Delta H$ is maximal allowed height tolerance.

\section{Determination of Initial Values of Optimized Variables}

The convergence and convergence rate in optimized design are closely related with initial value of design variables, so an important work for optimized design is to ascertain the initial values for the optimized design variables. For flanging of round hole on flat steel plate, pre-machined hole is normally calculated with isoline method, in which the flanging process is considered to be similar to the bending process, and hypothesis is that the radial length of plain lines in radial direction in the annular deformation zone around the round hole remain unchanged, and the forming process by flanging is thought of being formed by material thinning, this method is called isoline hypothesis.

Fig. 1 is a schematic description of the flanging process on tube, in order to facilitate research problems, followed main coordinate system is set up: the main axial axis of the tube as $X$ axis, the axial axis of the square tributary junction as $Z$ axis. Projection of flanged square tributary junction on tube is shown in fig. 2, the geometry is divided into three regions according to characteristics, i.e. cross-sectional zone, rounded transition zone and longitudinal cross-sectional zone. The cross-sectional zone refers to the segment of projection of the square hole, which parallel to Y-axis; longitudinal cross-sectional zone refers to the segment of projection of the square hole, which parallel to X-axis; rounded transition zone refers to the radius between the cross-sectional zone and longitudinal cross-sectional zone, as shown in fig. 2.

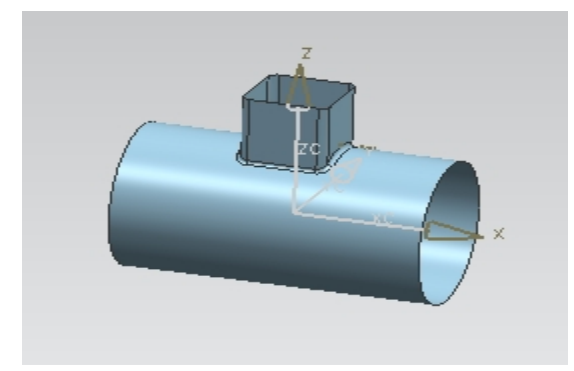

Fig. 1 Illustration of the coordinate system

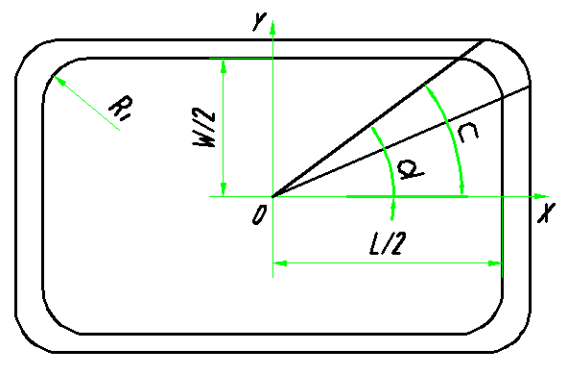

Fig. 2 Illustration of pre-machined hole

According to isoline theory, the length of the linear dimensions of material before and after the flanging process remains unchanged, in order to acquire this size, a plane is used, which passes through $\mathrm{Z}$ axis and inclines arbitrarily to the $\mathrm{X}$ axis, to cut the square tributary junction and the tube. A local coordinate system $X^{\prime} O Y^{\prime}$ is also set up, hereby the original $Z$ axis as $Y^{\prime}$ axis and the straight line, which inclines arbitrarily to the $X$ axis as $X^{\prime}$ axis, the section of the tube is an ellipse, its long axis is $R / \sin \theta$ and short axis is $R$, in which $0<\theta \leq \pi / 2$, as shown in fig. 3 . 


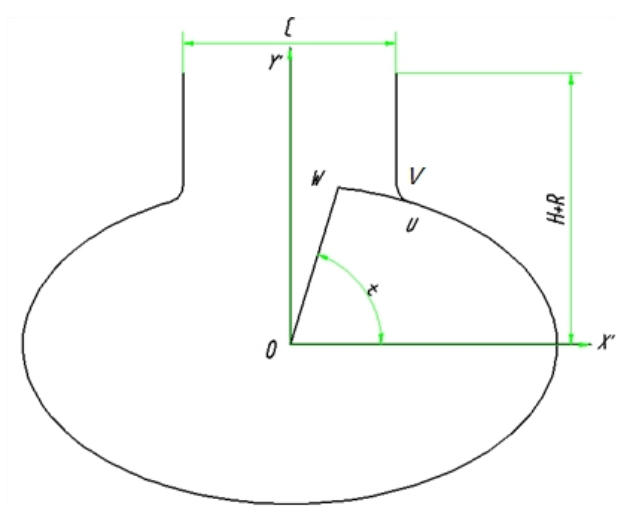

Fig. 3 Section in arbitrary angle

Based on relationship of geometry shown in the figure, the length of the straight wall portion after flanging is as follows:

$$
L_{1}=H+R-\sqrt{R^{2}-\left(\left(L / 2+R_{2}\right) \tan \theta\right)^{2}}-R_{2}
$$

The length of the rounded transition zone on tributary junction after flanging is:

$$
L_{2}=\pi R_{2} /(2 \cos \theta)
$$

The length before flanging equal to the length of the ellipse arc, i.e.:

$$
L=R \int_{t_{0}}^{t} \sqrt{(\sin t / \sin \theta)^{2}+(\cos t)^{2}} d t
$$

According to isoline theory, $L=L_{1}+L_{2}$, the value of parameter $t$ can be acquired through solving this equation, based on $\mathrm{t}$ it can be found out the coordinates on projection of point $\mathrm{W}$ of the plane is $(R \cos t / \tan \theta, R \cos t)$.

Similarly the mathematical model of the cross-sectional zone can be derived. For the rounded transition zone, it is difficult to determine the geometrical sizes, because this zone consists of a complicate spatial surface. Since the extension of the rounded transition zone is smaller compared with other zones, a simplified calculation hasn't any great influence on the total forming zones. Since rounded transition is adjacent to both of the areas, and calculations of the sizes for the pre-machined hole of the other two areas are completed, so the sizes of the pre-machined hole in the transition area can also be found out with the aid of intersectional points of transition area to the other two areas. It is replaced with an arc which goes through the two end points, the radius of the arc is determined by the ratio of sizes of the pre-machined hole to the flanged hole and the radius for flanging.

\section{Solution of Optimized Target Function}

The target function of optimized model built up in this paper is the mean square difference between practical flanged height and ideal height, and it is related to the shape and sizes of the flanged part. Because of the complex flanging process, it is very difficult to find out the values with conventional method, for this reason FE-method is used to simulate the forming process, and using the results file of the simulation to find out the shape and sizes of the formed parts, further to find out the solution to target function, mean time to judge the constraints.

Take a forming process as an example, in which outside diameter of the tube $114 \mathrm{~mm}$, square tributary junction width $55 \mathrm{~mm}$, square tributary junction length $55 \mathrm{~mm}$, transition radius of square $8 \mathrm{~mm}$, radius for flanging $5 \mathrm{~mm}$, flanged height $6 \mathrm{~mm}$, wall thickness of tube $2 \mathrm{~mm}$, the FE model built is shown in fig. 4. The target function of optimized model built in this paper is related to the flanged height, which can be read out from post-processing. 


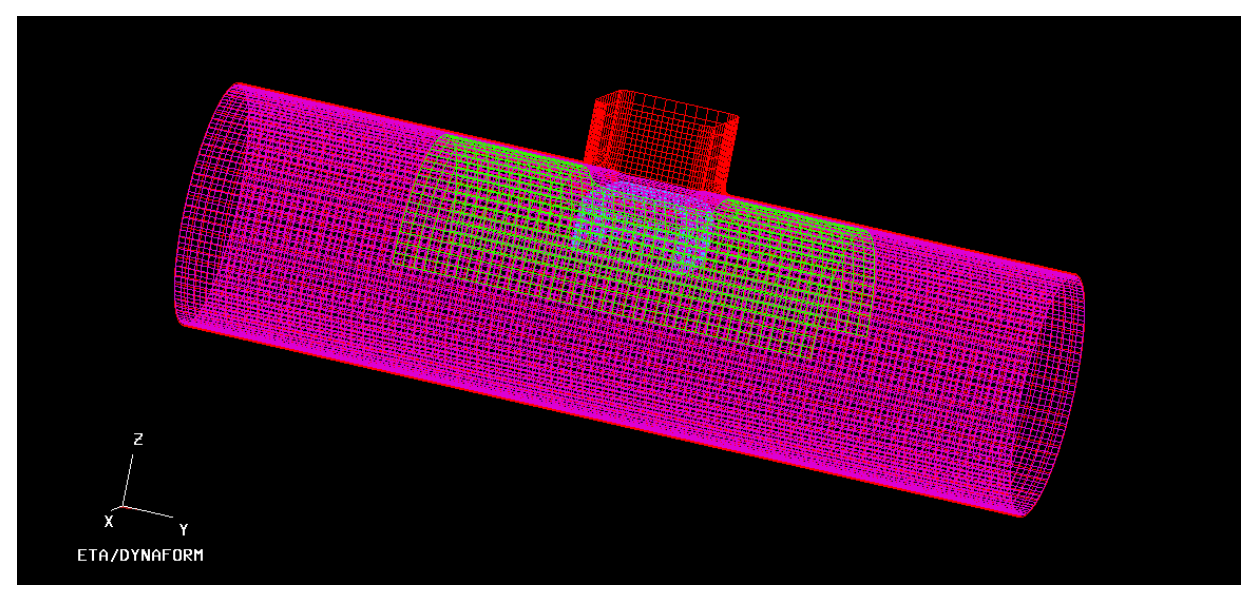

Fig. 4 Model of FE Simulation

\section{Optimized Design}

Based on the previous optimized design model and solving methods, pre-machined hole for flanging of square tributary junction on tube has been designed optimally, its parameters are: outside diameter of tube $114 \mathrm{~mm}$, width of square tributary junction $55 \mathrm{~mm}$, length of square tributary junction $55 \mathrm{~mm}$, transition radius for square $8 \mathrm{~mm}$, flanging radius $4 \mathrm{~mm}$, flanged height $4 \mathrm{~mm}$, wall thickness of tube $2 \mathrm{~mm}$. After optimization the mean flanged height is $59.98 \mathrm{~mm}$, mean square difference is 0.22 , maximal value is 60.44 , minimal value is $59.53 \mathrm{~mm}$, and maximal height deviation is $0.91 \mathrm{~mm}$. The flanged part after optimized calculation is shown in fig. 5 , it can be seen that the end of the opening is very flat, and there isn't wrinkle and crack, it meets the technical requirements.

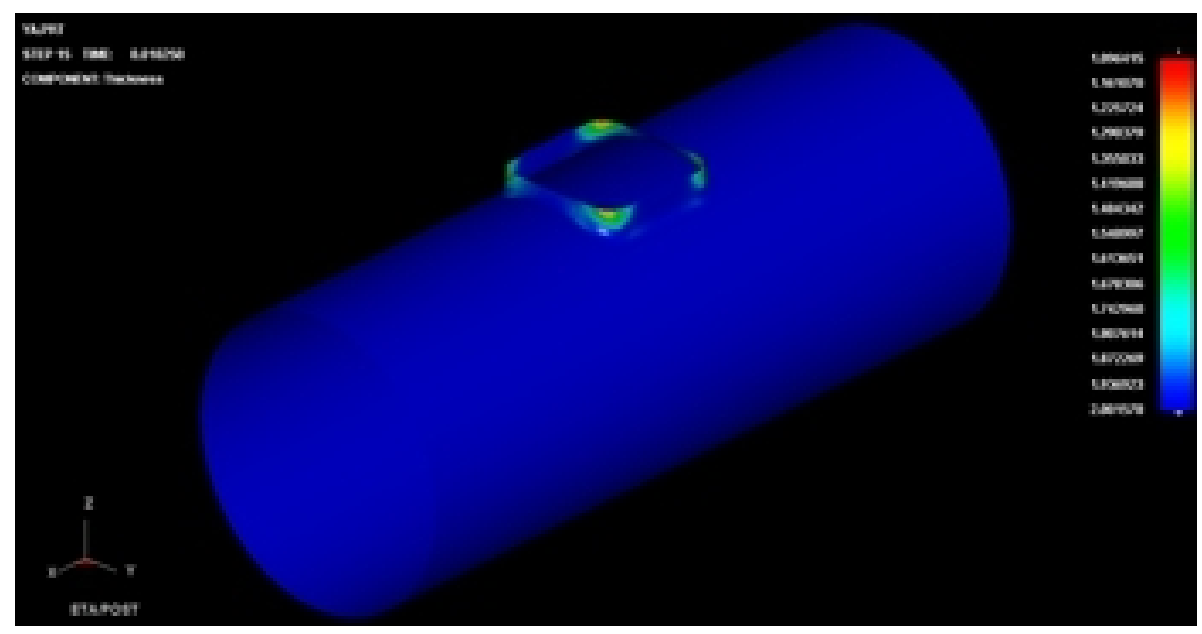

Fig. 5 Results of the optimized design

\section{Summary}

The optimized design of pre-machined holes for flanging of square tributary junction on cylindrical steel tube has studied. An optimized design model for pre-machined hole on tube for flanging of square tributary junction on cylindrical tube is established. The solved values from mathematical model are used as initial values for optimized design, while FE simulation results are used as target function solver, to study the shape and sizes of the pre-machined hole for flanging of square tributary junction on cylindrical tube. Example of optimized design shows that the optimized design results meet the technological requirements. 


\section{Acknowledgements}

This work was supported by the Doctoral Foundation of Shandong Jianzhu University(XNBS1245).

\section{References}

[1] Luo Yatao. Circle Flange Forming by Prefabricated Elliptical hole in Stainless Steel elbow, Journal of Rocket Propulsion,2(2009)50-53.

[2] Liu jiansheng, Wang Bing, Tian Jihong. Experimental and Simulative Study of Hole Flanging on Thick-Wall Cylinders with Nozzles,Journal of Plasticity Engineering,12(2005)74-76.

[3] Wang Bing, Liu jiansheng. Punch Types Effects on Hole Flanging of Thermal Thick-Wall Cyliners, Journal of Taiyuan University of Technology,3(2005)161-164.

[4] Zhang Yaqing, Wang Bing, Liu Jiansheng. Theotetical and Experimental Research of Hole Flanging on Thick-wall Cylinders with Nozzles, Journal of Taiyuan University of Technology, 4(2006) 437-439.

[5] Liu limin, Zhong Zhiping, Xie Tan. Numerical simulation and Experimental Study on the Drawing Procedure of 508mm Equal Diameter Tee,"Journal of Plasticity Engineering,5(200)15- 20.

[6] Li Zhaodong, Yu Jingzhi, Wang Zhonglei, Chen jun. Study of Flanging of Bypass on Three-way Steel Pipe, Hot Working Technology,19(2010)104-106.

[7] Bai Yanchao, Chen Jieshi, Chen Jun. Optimum Design of Complex Flanging Trimming Line Based on Error-Correction Method,".Journal of ShanHai JiaoTong University, 9(2010)1201-1205.

[8] Gu Li, Zhang Jian, Zhu Liang. Parameter optimization of larger-diameter T-tube flanging process,Forging and Stamping Technology,3(2009)71-75. 